\title{
Patterns of Dystrophin Gene Deletion/Duplication in a Sample of Saudi Patients with Duchenne Muscular Dystrophy
}

\author{
Ayman Abdelhady ${ }^{1}$, Salem Abdelhady ${ }^{2 *}$ and Hebatallah Rashed ${ }^{3}$ \\ ${ }^{1}$ Department of Otolaryngology, Ain Shams University, Cairo, Egypt; ${ }^{2}$ Department of Neurology, Ain Shams University, Abbasia, Cairo, \\ Egypt; ${ }^{3}$ Department of Neurology, Hospital for Special Surgery, New York, USA
}

\begin{abstract}
Introduction: Duchenne muscular dystrophy (DMD) is caused by the lack of functional dystrophin molecules, either due to nonsense mutations (premature stop codons) or by large rearrangements (deletions or duplications) that disturb the reading frame and in consequence abolish the production of dystrophin in muscles.

Methods: Twenty patients with muscular dystrophy diagnosed by clinical history, family pedigree, CK total and histopathology of muscle biopsy is subjected to screening for all 79 exons of dystrophin gene for deletions and duplications.

Results and Discussion: Deletion was detected in $80 \%$ of patients, while $15 \%$ showed duplication, one patient shows nucleotide substitution (c.10033C>T) in exon 69. Most common deletion found between exon 44 and 52 .

Conclusion: Our study detected high incidence of gene deletion compared to other studies, the most common deletion is multi exon deletion in the major hot spot of the gene (exon 44-52), also we detected lower incidence of duplication with higher percentage of duplication found distally.
\end{abstract}

Keywords: Duchenne muscular dystrophy; Dystrophen gene; Mutation; Deletion; Duplication

Abbreviations: BMD: Becker Muscular Dystrophy; CK: Creatine Kinase; DMD: Duchenne Muscular Dystrophy; MLPA: Multiplex Ligation-Dependent Probe Amplification; NCNP: National Centre of Neurology and Psychiatry.

\section{Introduction}

Duchenne muscular dystrophy (DMD) is an X-linked recessive disorder that affects 1 in 3,500 males and is caused mutations in the dystrophin gene. The gene is the largest in the human genome, encompassing 2.6 million base pairs of DNAs and containing 79 exons. DMD occurs either due to nonsense mutations (premature stop codons) or by large rearrangements (deletions or duplications) that disturb the reading frame of the dystrophin gene and in consequence abolish the production of dystrophin in muscles [1]. Dystrophin is located primarily in muscles used for movement (skeletal muscles) and in heart (cardiac) muscle. Dystrophin has a major structural role in muscle as it links the internal cytoskeleton to the extracellular matrix, strengthening the muscle fibers and protecting them from injury as muscles contract. Dystrophin is thought to serve as a shock absorber protein to protect muscle cells from movement-induced damage [2].
Advances in molecular diagnosis [3,4] and therapeutic strategies [5] have resulted in extended survival for patients with DMD [6]. Novel therapeutic strategies are involving the replacement of the gene (cell-based therapies), exogenous delivery of functionally engineered dystrophin gene constructs (gene therapy) or by repairing the endogenous locus [7].

Correct diagnosis is important for assessing whether patients are eligible for gene repair therapies which are dependent on the type of mutation. Therefore, a complete genetic screening that allows the exact characterization of the mutation will determine the best targets for exon skipping and that may differ among populations. In the current study, our objective is to study different gene mutations among Saudi Arabian patients and to establish a national registry of DMD patients and gene database which will give our patients an access to available genotype-based therapies and novel clinical trials.

Correspondence to: Salem Abdelhady, Lecturer, Department of Neurology, Ain Shams University, Abbasia, Cairo, Egypt, Tel: 00201282440741; E-mail: Salim.taha@gmail.com

Received: February 11, 2019, Accepted: March 01, 2019, Published: March 07, 2019

Citation: Abdelhady A, Abdelhady S, Rashed H (2019) Patterns of Dystrophin Gene Deletion/Duplication in a Sample of Saudi Patients with Duchenne Muscular Dystrophy. Biomedical Journals. 8:252. doi: 10.35248/2168-975X.19.8.252

Copyright: (c) 2019 Abdelhady A, et al. This is an open-access article distributed under the terms of the Creative Commons Attribution License, which permits unrestricted use, distribution, and reproduction in any medium, provided the original author and source are credited. 


\section{Patients and Methods}

Cross-sectional observational studies involving twenty patients with progressive muscular dystrophy have been referred to neurology clinic in Saudi German Hospital, Jeddah between 2006 and 2016. All patients were subjected to full clinical examination, family pedigree, serum Creatine Kinase (CK) levels.

Inclusion criteria for selection of patients were done according to the clinical criteria of DMD/BMD proposed by Jennekens et al. in 1991 [8]. DMD patients were diagnosed according to the age of onset where symptoms are present before the age of 5 years, with clinical sign comprise progressive symmetrical muscle weakness: proximal limb muscles more than distal muscles: initially only lower limb muscles. Calf hypertrophy is often present and wheelchair dependency before the age of 13 or better loss of unassisted ambulation before the age of 13 as suggested by Miller in 1992 [9].

Dystrophin gene testing was done using two milliliters of whole blood from patients, collected in sterile vacutainer tube after receiving informed consent. Genomic DNA extraction was carried out from the peripheral blood sample using Pure link genomic DNA extraction and purification Kit.

Screening done for all 79 exons of dystrophin gene for deletions and duplications sparing one or more exons was performed by either multiplex PCR or Multiplex Ligation-dependent Probe Amplification (MLPA) analysis (MLPA DMD kits P034/P035 (MRC Holland)). Dystrophin gene analysis was done in the National Centre of Neurology and Psychiatry (NCNP) Kodaira, Tokyo. The procedures followed in our study were in accordance with the ethical standards of the responsible committee on human experimentation (institutional or regional) and with the Helsinki Declaration of 1975 as revised in 2000.

\section{Results}

A total of 20 patients were enrolled in the study between 2006 and 2016, all of them were males, the age varies, the youngest being 6 years of age and the oldest is 26 years with a mean age of 10.9. Dystrophin gene deletion was detected in 16 patients out of $20(80 \%)$, while three patients only (15\%) showed duplication. Duplication was seen in exon 8-9 in patient number 3, in exon 44 50 in patient number 9 and in exon 31-43 in patient number 19.

Only one patient (Patient number 8) had neither deletion nor duplication, the MLPA analysis showed that the quantitative value of exon 69 was slightly but significantly reduced. Such a phenomenon is known to occur when there is a sequence variation within the sequence to which the MLPA probe hybridizes. So, we amplified exon 69 by PCR from genomic DNA of the patient, then sequenced the PCR product by Sanger method using DNA sequencer (Applied Biosystems 3130XL), the result of Sanger sequencer showed nucleotide substitution (c.10033C>T) (Fig. 1) in exon 69 (Table 1).

Four patients (25\%) out of 16 with dystrophin gene deletion had only one exon deletion, the most frequently deleted exon was exon 45 ( 2 patients), followed by exon 51 (one patient), the fourth patient (patient number 5) shows deletion mutation in exon 33 (Table 1). The other 12 patients with dystrophin gene deletion had multiple exon deletion (19 exons) most of which in the major hotspot region between exons 44 and 52, and only one patient (number 2) the deletion involves exons 8-18 (Figures 1 and 2). Interestingly, we

Table 1: Demographic data and frequency distribution of deletions in different exons.

\begin{tabular}{|c|c|c|c|c|c|}
\hline Serial & Phenotype & Age (yrs) & $\begin{array}{c}\text { X linked } \\
\text { family history }\end{array}$ & Intragenic deletion & Intragenic duplication \\
\hline 1 & DMD & 13 & No & Exon $45-45$ & No duplication \\
\hline 2 & DMD & 7 & No & Exon 8-18 & No duplication \\
\hline 3 & DMD & 10 & No & No Deletion & Exon 8-9 \\
\hline 4 & DMD & 14 & Yes & Exon $51-51$ & No duplication \\
\hline 5 & DMD & 8 & No & Exon 33 (deletion mutation) & No duplication \\
\hline 6 & DMD & 12 & Yes & Exon $45-48$ & No duplication \\
\hline 7 & DMD & 10 & Yes & Exon $45-48$ & No duplication \\
\hline 8 & DMD & 12 & Yes & No deletion, No duplication & Nucleotide substitution c. $10033 \mathrm{c}>\mathrm{t}$ Exon $69^{*}$ \\
\hline 9 & DMD & 6 & No & No Deletion & Exon $44-50$ \\
\hline 10 & DMD & 9 & No & Exon $48-52$ & No duplication \\
\hline 11 & DMD & 26 & Yes & Exon $46-47$ & No duplication \\
\hline 12 & DMD & 15 & Yes & Exon $45-54$ & No duplication \\
\hline 13 & DMD & 16 & Yes & Exon $46-47$ & No duplication \\
\hline 14 & DMD & 7 & No & Exon $45-50$ & No duplication \\
\hline 15 & DMD & 10 & Yes & Exon $45-45$ & No duplication \\
\hline 16 & DMD & 9 & No & Exon $45-50$ & No duplication \\
\hline 17 & DMD & 10 & No & Exon $45-52$ & No duplication \\
\hline 18 & DMD & 6 & No & Exon $45-52$ & No duplication \\
\hline 19 & DMD & 10 & No & No Deletion & Exon $31-43$ \\
\hline 20 & DMD & 8 & No & Exon $45-52$ & No duplication \\
\hline
\end{tabular}

DMD: Duchenne Muscular Dystrophy

"The MLPA shows no deletion or duplications spanning one or more exons, however the amount of MLPA product of exon 69 was somewhat reduced. That phenomenon is often caused by sequence variation on the MLPA probe site. Thus Exon 69 was sequenced, and nucleotide substitution was found as mentioned. 


\section{Dystrophin gene Multiplex PCR}

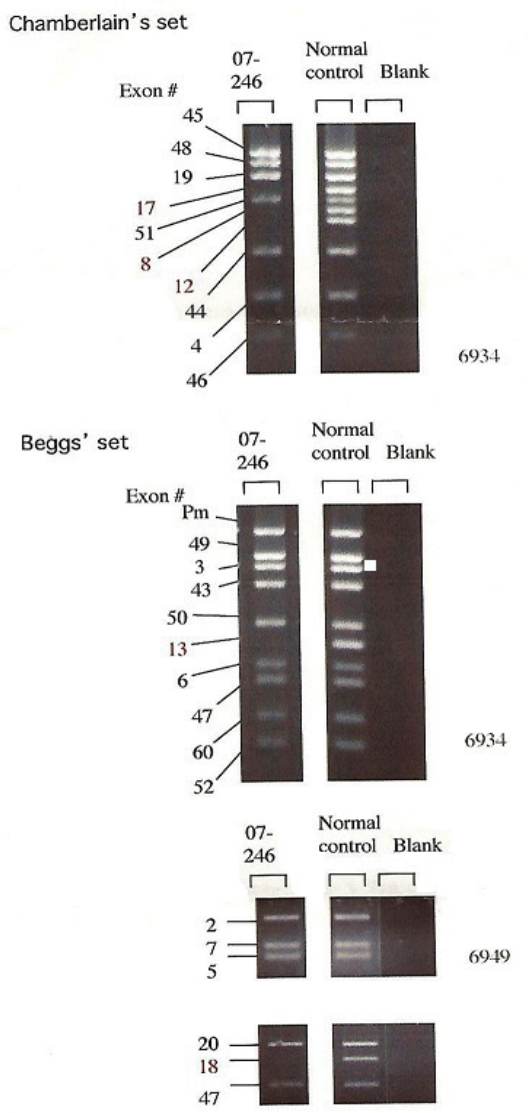

07-246: Deletion of exons 8-18

Section of DNA diagnosis, NCNP, JAPAN

Figure 1: Patient number 2 with dystrophin gene deletion at exon 8-18. The Chamberlain set shows absent exons 17, 8 and 12. The Beggs-set shows absent exon $13.149 \times 282 \mathrm{~mm}(96 \times 96 \mathrm{DPI})$.

\section{Exon 69}

Reference sequence (NM_004006.2)

TGCTTTTTTCTGGTCGAGTTGCAAAAGGCC

$\begin{array}{lllllllllll}C & F & F & S & G & R & \text { V } & \text { A } & \text { K } & \text { G } & H\end{array}$
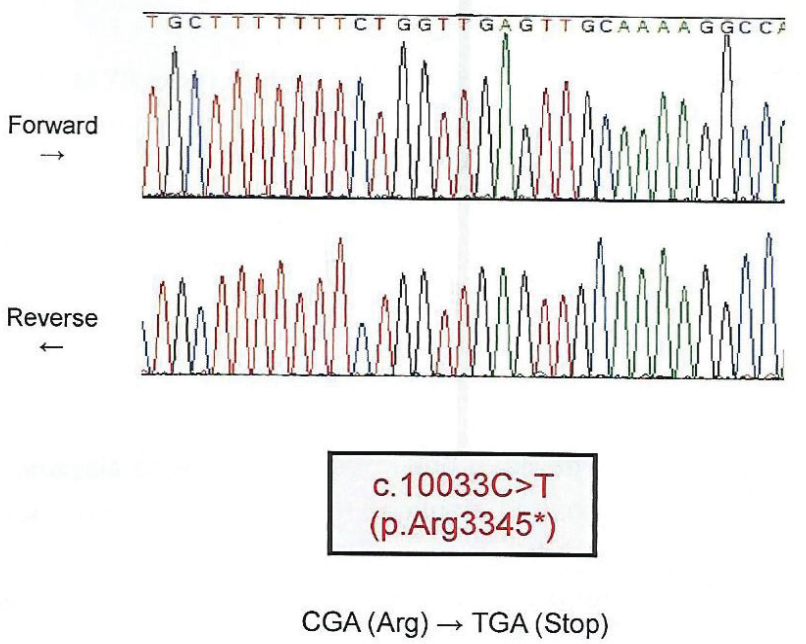

Figure 2: The other 12 patients with dystrophin gene deletion.

had 2 brothers underwent the study, both of them shows the same deletion in the same sequence of exons (45-48).

\section{Discussion}

Our study was done in a tertiary center in one of the largest Saudi Arabia cities (Jeddah), aiming to increase the attention to the molecular diagnosis of DMD in Arab population in general and Saudi patient especially and to identify the pattern of dystrophin gene mutation. Our study has shown the deletion of one or more exons of the dystrophin gene in $80 \%$ of patients, our result goes with results from Al-Jumah et al. in 2002 [10] targeting the Saudi patients and the study done in Kuwait (another Gulf country) showing $86 \%$ deletion ratio (Table 2 ), The rate of dystrophin gene deletion in our study was higher than the results obtained from similar Egyptian studies, 61.1\% [11], 52\% [12] and 55\% [13] as well as from other populations like Turkish, Greek, Moroccan and Iran (Table 2).

Regarding the pattern of the deletion, most of the patients $(75 \%)$ shows multiple exon deletion (19 exons) within the central hotspot of the gene between exons 44-52, only one patient shows multiple exon deletion between $8-18$, Our results goes with data received from previous studies and from other populations. In our study we also detected single exon deletion (exon 51 and exon 45) in 25\% of patient with dystrophin gene deletion. Among the twenty patients enrolled in the study, 15\% shows duplication in the dystrophin gene, similar low frequency of patient with gene duplication was found $(10.3 \%)$ in a study done by Tuffery-Giraud et al. in 2009 [14], while other studies in different population shows higher frequencies of duplication mutation as reported in Egyptian population (27.8\%) [15], Bulgarian population (27\%) [16] and Taiwanese population (24.7\%) [17].

Interestingly, in our study, duplications were located in the distal region of dystrophin gene. This contrasts with what was reported in Chinese population where a higher percentage of duplications are located in the proximal region (Exon 2-18) [18].

Recently in 2018, A study done in Saudi Arabia by Elhawary et al., [19] the authors used multiplex PCR and MLPA to identify gene mutation, they found $46.3 \%$ deletions and $53.7 \%$ duplications in the DMD gene, they also identified seven previously undescribed large DMD rearrangements. These new mutations included mixed rearrangement, large deletion, large duplications and double duplications.

This variation of the results may be explained by the fact that the population of the North West region of Saudi Arabia are not Native compared to the central region (Riyadh), with lower rate of consanguinity in the North west region compared to the central region $(44.1 \%$ versus $62.8 \%$ ) [20], also the higher rate of

Table 2: Comparison of frequency of deletions in different ethnic groups.

\begin{tabular}{cccc}
\hline Country & \% of deletion & Exon Tested & Authors \\
\hline Turkey & $59 \%$ & 18 exons & Battalogue et al. [22] \\
\hline Turkey & $52 \%$ & 10 exons & Kuseyri et al. [23] \\
\hline Greece & $63 \%$ & 18 exons & Florentin et al. [24] \\
\hline Kuwait & $86 \%$ & 25 exons & Haider et al. [25] \\
\hline Egypt & $55 \%$ & 18 exons & Effat et al. [13] \\
\hline Saudi Arabia & $78 \%$ & 25 exons & Al-Jumah et al. [10] \\
\hline Morocco & $59 \%$ & 18 exons & El-Sbiti et al. [27] \\
\hline Egypt & $52 \%$ & 10 exons & El-Hawary et al. [12] \\
\hline Egypt & $61.1 \%$ & 25 exons & El-Sherif et al. [11] \\
\hline Iran & $57.3 \%$ & 24 exons & Barzegar et al. [28] \\
\hline
\end{tabular}


intermarriage from other ethnical groups especially during Muslim immigration may be one of the reasons for this genetic variation.

In spite that point mutation is very difficult to detect due to the enormous size $(2.4 \mathrm{Mb})$ of the gene and its large transcript $(14 \mathrm{~kb})$ [21-28], however, we detected one patient with single nucleotide substitution (c.10033c>t) in Exon 69 and to our knowledge this mutation was not detected before by any other gene study in the region.

\section{Conclusion}

Our study revealed lower frequencies of duplication mutations (15\%) in Saudi patients with DMD with higher percentage of duplications located in the proximal regions compared to other populations in which duplication in the proximal region, also our study reported higher percentage of dystrophin gene deletions occurring in Saudi patients compared with other ethnic groups, Furthermore, we confirm in this analysis that the pattern of exon mutation is the same compared to other populations with some difference as mentioned above.

\section{REFERENCES}

1. Muntoni F, Torelli S, Ferlini A. Dystrophin and mutations: One gene, several proteins, multiple phenotypes. Lancet Neurol. 2003;2:731-740.

2. Ervasti JM, Sonnemann KJ. Biology of the striated muscle dystrophinglycoprotein complex. Int Rev Cytol. 2008;265:191-225.

3. Lopez-Hernandez LB, Ayala-Madrigal ML, Van Heusden D, Estrada-Mena FJ, Canto P, et al. Improvements in the diagnosis of dystrophinopathies: What have we learnt in these last 20 years? Rev Neurol. 2011;52:239-249.

4. Bunyan DJ, Skinner AC, Ashton EJ, Sillibourne J, Brown T, et al. Simultaneous MLPA-based multiplex point mutation and deletion analysis of the dystrophin gene. Mol Biotechnol. 2007;35:135-140.

5. Bushby K, Finkel R, Birnkrant DJ, Case LE, Clemens PR, et al. Diagnosis and management of duchenne muscular dystrophy, part 1: Diagnosis, and pharmacological and psychosocial management. Lancet Neurol. 2010;9:77-93.

6. Moxley RT, Pandya S, Ciafaloni E, Fox DJ, Campbell K Change in natural history of duchenne muscular dystrophy with long-term corticosteroid treatment: Implications for management. J Child Neurol. 2010;25:1116-1129.

7. Seto JT, Bengtsson NE, Chamberlain JS. Therapy of genetic disordersnovel therapies for duchenne muscular dystrophy. Curr Pediatr Rep. 2014;2:102-112.

8. Jennekens GFI, Ten Tate LP, De Visser M, Wintzen AR. Diagnostic criteria for Duchenne and Becker muscular dystrophy and myotonic dystrophy. Neuromuscul Disord.1991;1:389-391.

9. Miller G. Diagnostic criteria for Duchenne and Becker muscular dystrophy. Neuromusc Disord. 1991;1:389-391.

10. Al-Jumah M, Majumdar R, Al-Rajeh S, Chaves-Carballo E, Salih $\mathrm{MM}$, et al. Deletion mutations in the dystrophin gene of Saudi patients with Duchenne and Becker muscular dystrophy. Saudi Med J. 2002;12:1478-1482

11. El-Sherif RM, Aly Fahmy N, Nonaka I, Etribi MA. Patterns of dystrophin gene deletion in Egyptian Duchenne/Becker muscular dystrophy patients. Acta Myol.2007;3:147-152.
12. Elhawary Nasser A, Shawky RM, Hashem N. Frame shift deletion mechanisms in Egyptian Duchenne and Becker muscular dystrophy families. Mol Cells. 2006;39:758-761.

13. Effat LK, El Harouni AA, Amr KS. Screening of dystrophin gene deletions in Egyptian patients with DMD/BMD muscular dystrophies. Dis Markers. 2000;16:125-129.

14. Tuffery-Giraud S, Beroud C, Leturcq F, Yaou RB, Hamroun $\mathrm{D}$, et al. Genotype-phenotype analysis in 2,405 patients with a dystrophinopathy using the UMD-DMD database: A model of nationwide knowledgebase. Hum Mutat. 2009;30:934-945.

15. Shawky RM, Elsayed SM, Todorov T, Zibert A, Alawbathani S, et al. Non-deletion mutations in Egyptian patients with Duchenne muscular dystrophy. Egyptian Journal of Medical Human Genetics. 2014;15: 235-240.

16. Todorova A, Todorov T, Georgieva B, Lukova M, Guergueltcheva $\mathrm{V}$, et al. MLPA analysis/complete sequencing of the DMD gene in a group of Bulgarian Duchenne/Becker muscular dystrophy patients. Neuromuscul Disord. 2008;18:667-670.

17. Hwa HL, Chang YY, Chen CH, Kao YS, Jong YJ, et al. Multiplex ligation-dependent probe amplification identification of deletions and duplications of the Duchenne muscular dystrophy gene in Taiwanese subjects. J Formos Med Assoc. 2007;106:339-346.

18. Wang Q, Yang X, Yan Y, Song N, Lin C, et al. Duchenne or Becker muscular dystrophy: a clinical, genetic and immunohistochemical study in China. Neurol India. 2011;59:797-802.

19. Elhawary N, Jiffri E, Jambi S, Mufti A, Dannoun A, et al. Molecular characterization of exonic rearrangements and frame shifts in the dystrophin gene in Duchenne muscular dystrophy patients in a Saudi community. Human Genomics. 2018;12:18.

20. El-Hazmi MA, El-Swailem AR, Warsy AS, Al-Swailem AM, Sulaimani $\mathrm{R}$, et al. Consanguinity among the Saudi Arabian population. J Med Genet. 1995;32:623-6.

21. Chaturvedi LS, Mukherjee M, Srivastava S, Mittal RD, Mittal B. Point mutation and polymorphism in Duchenne/Becker muscular dystrophy D/BMD patients. Exp Mol Med. 2001;33:251-256.

22. Battaloglu E, Telatar M, Deymeer F, Serdarollu P, Kuseyri F, et al. DNA analysis in Turkish Duchenne/Becker muscular dystrophy families. Hum Genet. 1992;89:635-639.

23. Kuseyrei GN, Topalogulu H, Yuksel-Apak M. Screening of deletions and RFLP analysis in Turkish DMD/BMD families by PCR. Clin Genet. 1993;43:261-266.

24. Florentine L, Mavrou A, Kekou K, Metaxotou C. Deletion patterns of Duchenne and Becker muscular dystrophies in Greece. J Med Genet. 1995;32:48-51.

25. Haider MZ, Bastaki L, Habib Y, Moosa A. Screening 25 dystrophin gene exons for deletions in Arab children with Duchenne muscular dystrophy. Human Heredity. 1998;48:61-66.

26. Swaminathan B, Shubha GN, Shubha D, Murthy AR, Kumar HK, et al. Duchenne muscular dystrophy: A clinical, histopathological and genetic study at a neurology tertiary care center in Southern India. Neurology India. 2009;57:734.

27. El-Sbiti A, El-Kerch F, Sefiani AA. Analysis of Dystrophin gene deletions by multiplex PCR in Moroccan patients. Journal of Biomedicine and Biotechnology. J Biomed Biotechnol. 2002;2:158-160.

28. Barzegar M, Habibi P, Bonyady M, Topchizadeh V, Shiva S. Exon deletion pattern in Duchene Muscular Dystrophy in North West of Iran. Iran J Child Neurol. 2015;9:42-48. 